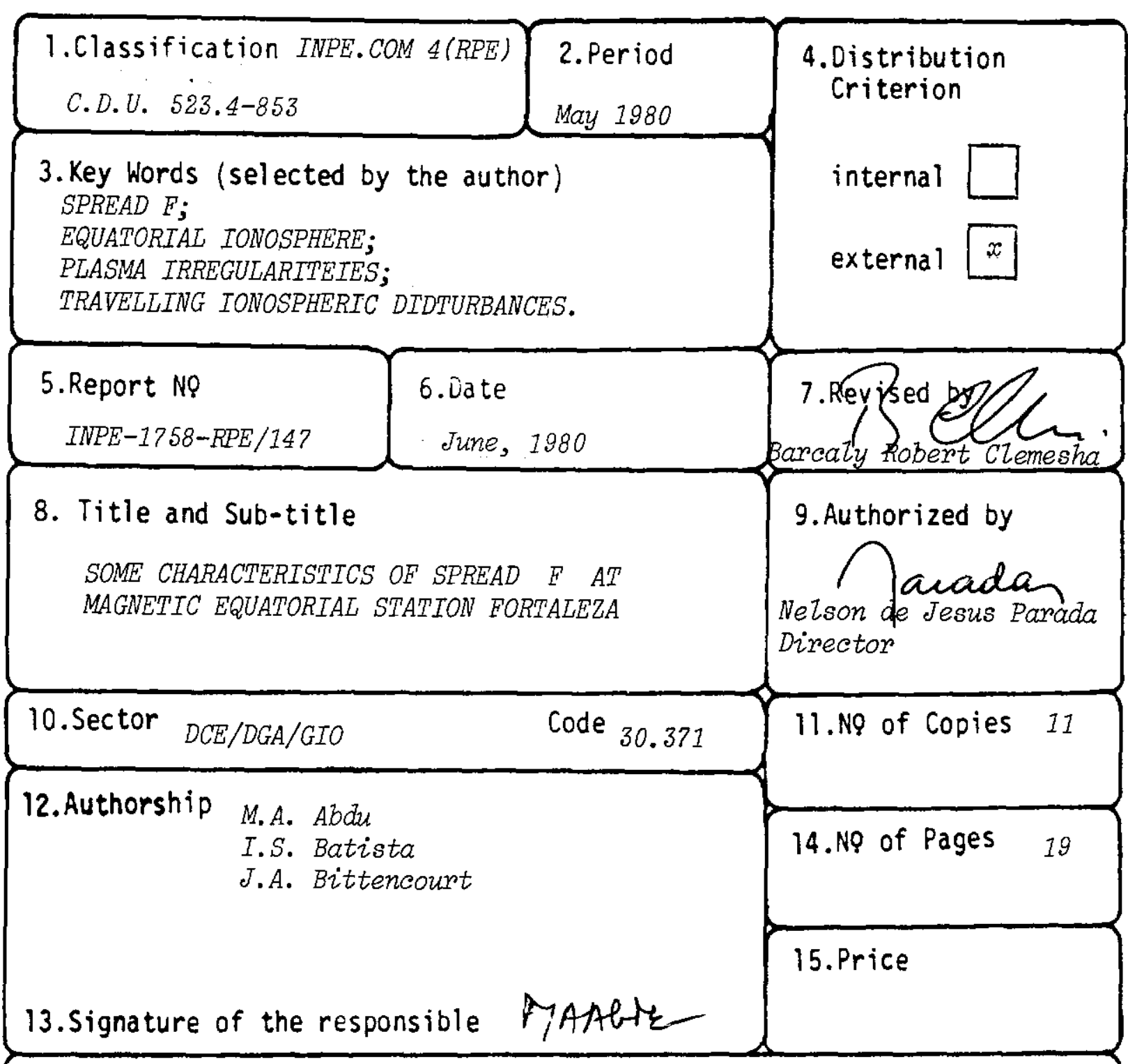

16. Summary/Notes Spread $F$ in ionograms of both the range and frequency spread types are studied for the magnetic equatorial station Fortaleza $\left(38^{\circ} \mathrm{W}, 3^{\circ} \mathrm{S}\right)$ for a one year period during 1978-79. TID type disturbances in the evening equatorial ionosphere are found to be a necessary prerequisite for the generation of the instabilities giving rise to the range type spread $F$, whereas frequency type spread $F$ is formed under different circumstances. Stricking differences are noted in the spread $F$ characteristics and related parameters over Fortaleza as compared to Huancayo and Jicamarca, situated within only $38^{\circ}$ in longitude west of Fortaleza. The post sunset maximom in $h^{\prime} F$, in winter, is delayed by about $1 \frac{1}{2} h r$ with respect to other seasons over Fortaleza, as compared to Huancayo, where it occurs earlier in winter than in other seasons. Similar differences exist also in the prereversal peak near sunset in the vertical drift velocity $\left(V_{z}\right)$ between Fortaleza and Jicamarca. The differences are attributed possibly to the large difference in the magnetic field declination and to other factors such as the difference in the magnetic field intensity and the relative separation between geogrophic and magnetic equators that exist between Fortaleza and the other stations.

17. Remarks This work was partially supported by the "Fundo Nacional de De senvolvimento Cientifico e Tecnológico (FNDCT)", Brazil, under contract FINEP-537/CT. 


\title{
SOME CHARACTERISTICS OF SPREAD F AT \\ MAGNETIC EQUATORIAL STATION FORTALEZA
}

\author{
M.A. Abdu, I.S. Batista and J.A. Bittencourt \\ Instituto de Pesquisas Espaciais - INPE \\ Conselho Nacional de Desenvolvimento Cientîfico e Tecnológico - CNPq \\ 12200 São Josē dos Campos, S.P., Brasit
}

ABSTRACT

Spread $F$ in ionograms of both the range and frequency spread types are studied for the magnetic equatorial station Fortaleza $\left(38^{\circ} \mathrm{W}, 3^{\circ} \mathrm{S}\right)$ for a one year period during 1978-79. TID type disturbances in the evening equatorial ionosphere are found to be a necessary prerequisite for the generation of the instabilities giving rise to the range type spread $F$, whereas frequency type spread $F$ is formed under different circumstances. Stricking differences are noted in the spread $\mathrm{F}$ characteristics and related parameters over Fortaleza as compared to Huancayo and Jicamarca, situated within only $38^{\circ}$ in longitude west of Fortaleza. The post sunset maximum in $h^{\prime} F$, in winter, is delayed by about $1 \frac{1 / 2}{2} \mathrm{hr}$ with respect to other seasons over Fortaleza, as compared to Huancayo, where it occurs earlier in winter than in other seasons. Similar differences exist also in the prereversal peak near sunset in the vertical drift velocity $\left(V_{z}\right)$ between Fortaleza and Jicamarca. The differences are attributed possibly to the large difference in the magnetic field declination and to other factors such as the difference in the magnetic field intensity and the relative separation between geographic and magnetic equators that exist between Fortaleza and the other stations. 


\title{
SOME CHARACTERISTICS OF SPREAD F AT \\ MAGNETIC EQUATORIAL STATION, FORTALEZA
}

\author{
M.A. Abdu, I.S. Batista and J.A. Bittencourt \\ Instituto de Pesquisas Espaciais - INPE \\ Conselho Nacional de Desenvolvimento Cientĩfico e Tecnolögico - CNPq \\ 12200 São Josē dos Campos, S.P., Brasil
}

INTRODUCTION

Equatorial ionospheric irregularities have been investigated somewhat extensively from ionosonde observations ever since the first study by Booker and Wells (1938) of the diffuse echoes, or spread $F$ traces, in the ionograms over Huancayo. Recent efforts to study these irregularities by VHF radars, satellite scintillation technique, in situ measurements by satellite and rockets, and theoretical modeling (Farley et a1., 1970; Balsley et al., 1972; Woodman and LaHoz, 1976; Morse et a1., 1977; Kelley et al., 1976; Basu and Kelley, 1979; Ossakow et al., 1979) have resulted in impressive progress in our understanding of their generation and morphology. Since the different scale sizes in the irregularity spectrum, sensitive to the different techniques, seem to coexist in the average nighttime equatorial ionosphere (with important exceptions, however), a study of only part of this spectrum using a single instrument, such as ionosonde, can still yield valuable results. In fact, for morphological studies, the ionosonde remains one of the most powerful tools.

An important aspect of the equatorial spread $F$ morphology is its longitudinal variation as seen in the higher incidence rate of irregularities in the Atlantic zone, observed from OGO 6 results by Hanson and Sanatani (1971) (and more recently by Basu and Basu, 1976). In fact, there is a marked increase in the occurrence rate of the irregularities within a few degrees east of Huancayo, where the magnetic declination angle attains a global maximum along the equator. There has been a suggestion that this increased occurrence rate is possibly caused by an increased interaction of the neutral atmosphere 
dynamics in the ionospheric irregularity process (Hanson et al.,1973). However, no study of the spread $F$ activity has so far seems to have been carried out over this region. The purpose of this paper is to present and discuss some results on spread $F$ occurrence and related ionospheric parameters, for a one year period (1978 - 79), from the ionograms taken at Fortaleza $\left(38^{\circ} \mathrm{W}, 3^{\circ} \mathrm{S}\right)$, where a $\mathrm{C}-4$ ionosonde has been in operation since 1975.

\section{SPREAD F DEVELOPMENT OVER FORTALEZA}

Satellite traces precede the diffuse echoes of the range type spread $F$ in the ionograms over Fortaleza in almost all cases, observed at 15 minutes intervals, in the one year period studied here. Precedence by the satellite traces has also been reported in the earlier studies for other equatorial stations (see for example Lyon et a].,1961). A sequence of ionograms selected from a set taken at one minute intervals is presented in Figure 1 to illustrate the time evolution of the satellite trace, starting from its first appearance on the first order trace up to the formation of the fully developed diffuse trace. When the first sign of the disturbance was visible, adjacent to the low frequency end of the first order trace at 0623, a diffuse trace of partially formed spread $F$ was already present in the second order mode. This suggests that the regions in the ionosphere, responsible for the two traces, were spatially separated, with the second order trace arising perhaps from a region eastward of that of the first order trace, as could be expected if the onset of the disturbance always occurred at a specific phase in the diurnal variation pattern of the relevant $F$ region parameters. In a few minutes, the initial trace gets enhanced and new ones appear, which in turn get enhanced as the previous one. The nature of the traces at this stage suggests reflection of the radio waves from thin layers, probably representing iso-phase surfaces on a ripple type disturbance, wherein the plasma frequency increases with time until the structure breaks up into progressively smaller reflecting surfaces, providing the multiple normals that constitute the diffuse echoes that characterize the spread $F$. The whole process in this particular event has taken about 
25 minutes, by which time, the regular F-region trace has moved upward leaving below the irregularity patches as seen in the ionogram at 0652 LT. The range spread, on this day, was present ti11 about 21 LT, after which the nature of the spread changed over to the frequency type. The last two ionograms show this transition, which, on this day, seems to be a result of the lowering of the layer relative to the irregularities. Frequency type spread develops more often, however, without preceded by the range type spread, as will be discussed later.

\section{OCCURRENCE RATE OF THE SPREAD F}

Figures 2 and 3 present a complete picture of the frequency of occurrence of both the range type and frequency type spread $F$ over Fortaleza, during the one year period August 1978 Juily 1979. The range type spread $F$, in Figure 2, includes also some traces that, at later hours in the night, have shown characteristics of frequency spread as well, whereas Figure 3 shows exclusively the frequency type spread $F$. A separate figure on the occurrence rate as a function of local time is not included here, since this information is already contained with much more detail in Figures 2 and 3 .

The evening onset of range type spread $F$ is seen to occur between 18 and $19 \mathrm{LT}$ (mostly near $18 \mathrm{LT}$ ). The onset of the frequency type is found to be near $20 \mathrm{LT}$ or later. These results suggest that the classification of the range and frequency types of spread $F$ as being premidnight (and post sunset) and post midnight phenomena, respectively, as observed over Thumba, India (Chandra and Rastogi, 1972; Rastogi and Woodman, 1978) is not valid for Fortaleza.

Seasonal variation is pronounced in both types of spread F. Range type has maximum occurrence rate in summer months (Nov., Dec., Jan.), in contrast to the equinoctial maximum observed over Thumba (Chandra and Rastogi, 1972) for similar phases of the solar activity cycle. Maximum occurrence in summer and equinoctial months (with stronger maximum in October) has been observed also over Ibadan (Lyon et a1., 1961) where the range type spread $F$ was mainly a premidnight phenomenon. On 
many summer nights over Fortaleza, the range spread, that starts during evening hours, continues till sunrise, which seems to indicate a much higher occurrence rate compared to Thumba, where Somayajulu et al. (1975) observed only 30 nights of continuous spread $F$ during the entire 1970 (sunspot numbers being nearly the same as those of 1978-79). The winter minimum in the range spread occurrence, seen in Figure 2, agrees with the results for Huancayo given by Rastogi and Vyas (1977). However, if we consider both types of spread $F$ together, Fortaleza shows peak occurrences in summer as well as in winter, and the overall occurrence rate seems to be higher than over Huancayo. The winter maximum in the occurrence of frequency type spread $F$, seen in Figure 3, contrasts with the summer maximum of the same type of spread $F$ for Huancayo presented by Rastogi and Vyas (1977). Thus, there seems to be important differences in the seasonal pattern of Fortaleza compared with those of the other magnetic equatorial stations. In particular, the difference from Huancayo, situated within only $38^{\circ}$ degrees of longitude from Fortaleza, is an important factor to be considered in the spread $F$ morphology. In Figure 2, we have marked intervals during which the $k_{p}$ values were $>5$ and an inverse relationship between magnetic activity and range spread seems to be present.

\section{F-LAYER HEIGHT VARIATIONS AND SPREAD F OCCURRENCE}

It has been observed by Farley et a1. (1970) that the onset of spread $F$ in the VHF radar results, over Jicamarca, was associated in many cases with the upward motion of the F-layer, in agreement with earlier observations with ionosonde. From their results, Farley et al. (1970) suggested that the bottom of the layer must be above some threshold altitude if the instability causing spread $F$ is to occur. Rastogi (1978) has suggested that the onset of range spread $F$ occurs around the periods of peak upward velocity (or around the prereversal maximum in the F-region drift velocity) and the drifts were downward during the later development of the irregularities as evident also in the results of Farley et a1. (1970). This feature has been observed also in the earlier back scatter results of Clemesha (1964) over Ghana. 
Results for Fortaleza are shown in Figure 4, presenting the monthly $\overline{h^{\prime} \mathrm{F}}$ variations form 1600 LT to 0600 LT for four months, June 1978, 79, September 1978, Apri1 1979 and December 1978, representing the winter, equinox and summer months. Also shown, in the same figure, are the F-region drift velocities $\left(V_{z}\right)$ derived as $d\left(\overline{h^{\prime} F}\right) / d t$, which could give essentially the same results as from a Doppler measurement of the true velocity (Farley et a 1., 1970), when the low lying ionization is small and the layer is sufficiently high. During post midnight hours, when the heights are generally lower, the inferred velocities might be, to some extent, underestimated, because of recombination processes. These factors are not likely to influence our present discussion, however.

During December (when the occurrence rate was the highest for a wide LT range) and September and April (when the rate was high especially in the hours immediately following sunset) there is excellent agreement between the times of the spread onset and the monthly mean prereversal peak in the drift velocity occurring around 18-1830 LT. The amplitude of the prereversal peak in $V_{z}$ is a maximum in December and the reversal in $V_{z}$ occurs earlier than in the other months, while $\overline{h^{\prime} \mathrm{F}}$ in December reached maximum somewhat higher and earlier than in the other two months (September and Apri1). These feature might have some influence on the duration of the spread $F$ events (1arges duration of more events being observed in December), which could be confirmed from a case by case study of a large number of individual events, which is not being attempted in the present work.

The month of June (when the occurrence rate of range type spread was a minimum, and that of frequency type was maximum) appears to be exceptional in the $\overline{h^{\prime} \mathrm{F}}$ variation as well, in the sense that the $\overline{h^{\prime} F}$ reaches the post sunset maximum significantly later (around $11 / 2$ hours) than in the other months, whereas it sould have occurred somewhat earlier and nearer to the time of the maximum observed over Huancayo, (Rastogi, 1978), since the difference between the summer and winter times of these maxima is expected to be smaller at 
Fortaleza, being closer to the geographic equator, than at Huancayo. The amplitude of the $V_{z}$ prereversal peak over Fortaleza is higher in summer and equinoxes than in winter, which agrees with VHF radar results for Jicamarca, presented by Fejer et a1. (1979). However, in our results, the time of the $V_{z}$ peak is considerably delayed in winter, quite contrary to that observed for Jicamarca (Fejer et al., 1979). This later occurrence in winter of the $\overline{h^{\prime} F}$ maxima as well the preversal peak in $V_{z}$, seems to be a genuine regular feature as it is seen reapeated consitently during 1978 and 1979. Fortaleza winter behaviour seems to correspond to northern hemisphere summer conditions. The cause of this remarkable difference between Huancayo and Fortaleza should probably be sought in the differences in the geomagnetic field configuration existing between these two magnetic equatorial stations in the American zone.

The range type spread $F$ occurs rarely over Fortaleza in winter months, which may be associated with the smaller amplitude in the prereversal peak in $V_{z}$ as well as its later time of reversal, as compared to the other months when the occurrence rate is higher. On the few days when it did occur, its onset seems to correspond to the time of the first of the two peaks in the $V_{z}$ prereversal enhancement present in June, as can be verified from Figures 2 and 4 (and also by examining many individual cases, though not shown here). On the other hand, the frequency type spread $F$ that has a maximum occurrence rate in the winter months seems to have its onset times within the time of the prereversal peak (the second peak) in $V_{z}$ that occurs at around $1930 \mathrm{LT}$ and the $V_{z}$ reversal time at about $2100 \mathrm{LT}$, in June, when $\overline{h^{\prime}} \bar{F}$ reaches its maximum.

\section{DISCUSSION AND CONCLUSIONS}

Satellite traces, whose time evolution was shown in Figure 1, were present as a precursor to almost al1 the cases of range type spread $F$ observed over Fortaleza (the very rare exceptions, perhaps one or two in the one year period, might be due to the time that the satellite trace takes to evolve into the range type spread, being less than the observation interval of 15 minutes). Satellite traces were also 
observed in the case of the range spread which occurred at later hours of the night, independent of whether or not a post sunset onset of the range spread had taken place on that day. Thus, it seems certain that the precedence by wave like or TID type disturbance is a necessary condition for initiating the generation of the irregularities giving rise to the range type spread $F$.

Booker (1979) has recently called attention to the important role of TID's in the generation of certain type of spread $F$ irregularities. A spectrum of TID's exists in the evening equatorial ionosphere and those TID's whose phase trace speeds are in the direction of, and, nearly equal to, the F-region drift velocity, get amplified by the spatial resonance mechanism (Rottger, 1978; Klostermeyer, 1978; Beer, 1974; Whitehead, 1971) until they are broken up giving rise to instabilities. However, the range type spread $F$ occurrences over Fortaleza, and possibly also over other equatorial stations, do not seem to corroborate the spatial resonance theory, at least in the early phase of the spread $F$ development, since the F-region drift was clearly upward (until about 20-21 LT) during the onset of the range spread in the ionogram, whereas the phase trace speed of the TID is known to be downward. On the other hand, the large density gradient of the bottom side $F$ layer at these times could be a decisive factor. For example, the condition for positive linear growth rate for the instabilities in the collisional Rayleigh - Taylor mode, given by 0ssakow et a1. (1979) is that $\left(d n_{0} / d h\right)\left(1 / n_{0}\right)\left(g / \nu_{i n}\right)>v_{R}$, where $\mathrm{dn}_{0} / \mathrm{dh}$ is the ambient electron density gradient, $g$ the gravitational acceleration, $v_{\text {in }}$ the ion-neutral collision frequency and $v_{R}$ the recombination rate. Evaluation of this expression using the ionograms, shows that this positive growth rate is amply satisfied during the sunset hours. Thus, the TID type disturbances might, perhaps, be providing only the initial perturbations in the ionospheric plasma upon which the Rayleigh - Taylor mechanism and possibly the $\underset{\sim}{E} \times \underset{\sim}{\operatorname{B}}$ gradient drift mechanism operates, causing the initial plasma density fluctuations to grow, until the irregularities turn into plasma density depletions, or bubbles, on the bottomside, which may then nonlinearly rise by polarization $E \times \underline{B}$ motion through the F-peak, which might be the cause 
of some frequency type spread.

Rastogi and Woodman (1978) has presented some results showing that VHF radar returns over Jicamarca arise from irregularities that coexist with those responsible for range type spread $F$, but not frequency type spread $F$, in the ionograms over Huancayo. Furthermore, from VHF radar results, Farley et al. (1970) have pointed that the bottom of the F-layer should be above a threshold level for the instability to occur (which according to Rastogi and Woodman (1978) should be related to range type spread $F$ ). Thus, our results for Fortaleza, showing rare occurrences of range type spread $F$ in June when, in fact, the $\overline{h ' F}$ post sunset peak was the highest during the year, would suggest that the requirement of a threshold altitude for the bottom of the F-layer is not a sufficient one. On the other hand, our observations seem to favor a threshold altitude for the occurrence of the frequency type spread.

One of the most interesting and significant features of the spread $F$ over Fortaleza is the high occurrence rate in winter months of frequency type spread $F$, as compared to Huancayo. It is important to note here that none of the cases of the frequency type spread was preceded by wave like disturbances (satellite traces) as was observed in the case of Range type spread F. Also, a vast majority of frequency type spread $F$ events do not represent an evolutionary phase of what might have started initially as a range type spread $F$ event, since most of the events observed in the winter months were not preceded by range type spread. Thus, it appears that there are, at least, two distinctly different circumstances in the equatorial ionosphere that favor generation of the instabilities responsible for the spread $F$ irregularities as observed by ionosonde. In the case of the irregularities giving rise to the frequency type spread F, since they occur near the F-layer peak, where the local electron density gradient could not be significant, the decisive factor in the generation of the instabilities could possibly be the height gradient in the field line integrated electron content, in the way discussed by Balsiey et al. (1972). 
Another important feature in the Fortaleza results is the later occurrence in winter (June) of the post sunset $\overline{\mathrm{h}^{\prime} \mathrm{F}}$ peak (that was higher than in other seasons) and the smaller amplitude of the prereversal peak in $V_{z}$ whose reversal occurrend significantly later than were observed over Huancayo (Rastogi and Vyas, 1977) and Jicamarca (Fejer et al., 1979). These features could be responsible, in some way, for the higher occurrence rate of frequency type spread $F$, in winter, since the onset times of most of these events, being around 2000 LT, seem to fall between the time of the prereversal $V_{z}$ peak, around 1930 LT and the $V_{z}$ reversal time, around $2100 \mathrm{LT}$ when the layer reaches its maximum height. The cause of these pronounced differences in the behaviour in the spread $F$ and related parameters between Fortaleza and Huancayo, separated by only $38^{\circ}$ of longitude, are not clearly understood. Important influencial factors could be the large difference in the magnetic declination angle (being Fortaleza at $20^{\circ} \mathrm{W}$ and Huancayo at $4^{\circ} \mathrm{E}$ ), the difference in the magnetic field intensity and the relative separation between geographic and magnetic equators, at the two locations, since they could produce different degrees of dynamical interaction between the neutral atmosphere and the ionospheric plasma at the two stations. Also, these factors would affect the vertical drift velocity, since it depends in a somewhat complex way on the magnetic field intensity and configuration. Further studies are continuing using simultaneous ionograms for longer periods and special time intervals for both Huancayo and Fortaleza.

\section{ACKNOWLEDGEMENTS}

This work was partially supported by Fundo Nacional de Desenvolvimento Cientifico e Tecnolögico (FNDCT) under Contract FINEP130/CT. The authors thank Dr. B.R. Clemesha for useful descussions. The $\mathrm{C}-4$ ionosonde at Fortaleza was supplied by the National Oceanic Atmospheric Administration, NOAA, Boulder, Co. 80302, USA. 


\section{REFERENCES}

Balsley, B.B., G. Haerendel, R.A. Greenwald, Equatorial spread F: recent observations and a new interpretation, J. Geophys. Res., 77, 5625-2628, 1972.

Basu, S. and S. Basu, Proc. COSPAR, Symposium on the Geophysical Use of Satellite Beacon Observation, Boston Univ., Boston, USA, 1976.

Basu, S. and M.C. Kelley, A review of recent observations of equatorial scintillations and their relationship to current theories of $F$ region irregularity generation, Radio Science, 14, (3), 471, 1979.

Beer, T., On the dynamics of equatorial spread F, Aust. J. Phys., 27, $391,1974$.

Booker, H.G., The role of acoustic gravity waves in the generation of spread $F$ and ionospheric scintillation, J. Atmos. Terr. Phys., 4l, $501,1979$.

Booker, H.G. and H.W. Well, Scattering of radio waves in the F-region of ionosphere, Terr. Magn. Atmosph. Eectr. , 43, 249, 1938.

Chandra, $H$ and R.G. Rastogi, Spread $F$ at magnetic equatorial station Thumba, Ann. Geophys., 28, 1, 37, 1972.

Clemesha B.R., An investigation of irregularities in the F-region associated with equatorial type spread F, J. Atmos. Terr. Phys., 26, $91,1964$.

Farley, D.T, B.B. Balsley, R.F. Woodman, J.P. McClure, Equatorial spread F: Implications of VHF radar observations, J. Geophys, Res., vol. 75, 7199-7210, 1970.

Fejer, B.G., D.T. Farley, R.F. Woodman and C. Calderon, Dependence of equatorial $F$ region vertical drift on season and solar cycle, J. Geophys. Res., 84, 5792, 1979. 
Hanson, W.B. and S. Sanatani, Relationship between $\mathrm{Fe}^{+}$ions and equatorial spread F, J. Geophys. Res., 76, 7761, 1971.

Hanson, W.B., J.P. MCClure and D.L. Sterling, On the cause of equatorial spread F, J. Geophys. Res., 78, 13 2353, 1973.

Kelley, M.C., G. Haerendel, H. Kappler, A. Valenzuela, B.B. Balsley, D.A. Carter, W.L. Ecklund, C.W. Carlson, B. Hausler and R. Torbert, Evidence for Rayleigh - Taylor type instability and upwilling of depleted density regions during equatorial spread $F$, Geophys. Res. Lett. , 3.448, 1976.

Klostermeyer, J., Nonlinear investigation of the spatial resonance effect in the nighttime equatorial $\mathrm{F}$ region, J. Geophys. Res., 83, $3753,1978$.

Lyon, A.J., N.J. Skinner and R.W. Wright, equatorial spread $F$ at Ibadan, Nigeria, J. Atmos. Terr. Phys., vol. 21, 100-119, 1961.

Morse, F.A., B.C. Edgar, H.C. Koons, C.J. Rita, W.J.Heikkila, J.H. Hoffman, B.A. Tinsley, J.D. Winningham, A.B. Christensen, R.F. Woodman, J. Pomalaza and N.R. Teixeira, Equion: an equatorial ionospheric irregularity experiment, J. Geophys. Res., 82, 578, 1977.

Ossakow, S.L., S.T. Zalesak, B.E. McDonald and P.K. Chaturvedi, Nonlinear quatorial spread $F$ : Dependence on altitude of the $F$ peak and bottomside background electron density gradient scale length, J. Geophys. Res., 84, 17, 1979.

Rastogi, R.G., On the equatorial spread F, Proc. Indian Acad. Sci., vol. $87 \mathrm{~A} 115,1978$.

Rastogi, R.G. and C.D. Vyas, Range and frequency spread F at Huancayo, Proc. Ind. Acad. Sci., 86, A(4), 417-421, 1977. 
Rastogi, R.G. and R.F. Woodman, VHF radio wave scattering due to range and frequency types of equatorial spread F., J. Atmos. Terr. Phys., 40, $485,1978$.

Rottger, J., Drifting patches of equatorial spread-F irregularities. An experimental support for the spatial reasonance mechanism in the ionospher, J. Atmos. Terr. Phys., 40, 1103, 1978.

Somayajulu, V.V., K. Sen Gupta, B.V. Krishana Murthy, Durattion of equatorial spread $F$, Nature, 257, 112, 1975.

Whitehead, J.D., Ionization disturbances caused by gravity waves in the presence of an electrostatic field and background wind, J. Geophys. Res., $70,238,1971$.

Woodman, R.F. and C. LaHoz, Radar observations of F-region equatorial irregularities, J. Geophys. Res., 81, 5447, 1976. 


\section{FIGURE CAPTIONS}

Fig. 1 - A sequence of ionograms showing the time evolution of the "satellite" trace, from its first appearance adjacent to the low frequency end of the first order F-trace (at 0623 LT) till the fully developed range type spread (at 0652 LT).

Fig. 2 - A complete history of range type spread $F$ occurrence from Aug. 1978 till July 1979. The vertical lines join the times in LT marked on the $y$-axis, at which the range type spread was observed on the individual days. The letter $C$ represents absense of data for consecutive days (horizontal occurrence), or for consecutive hours (vertical occurrence). Broken lines represent hourly observations.

Fig. 3 - A complete history of frequency type spread $F$ occurrence plotted as in Figure 2.

Fig. 4 - Variations with local time of the monthly mean height of the bottom of the F-layer, $\overline{h^{\prime} F}$, and the vertical F-region drift velocity $\left(V_{z}\right)$ calculated as $\frac{d}{d t}\left(\overline{h^{\prime} F}\right)$ for June 1978 and 79 , Sept. 78, and April 79. 


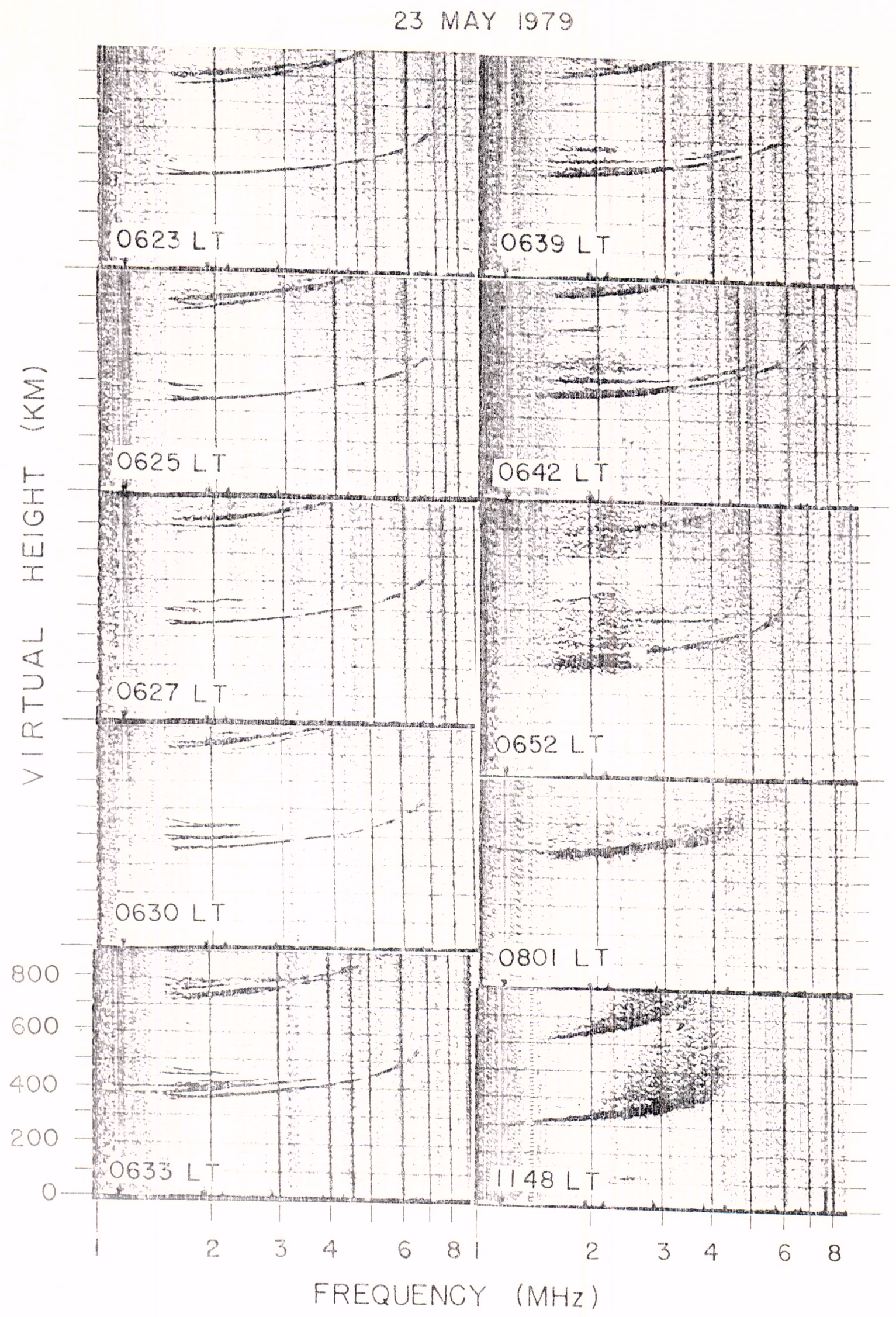

Fig. 1 
RANGE SPREAD

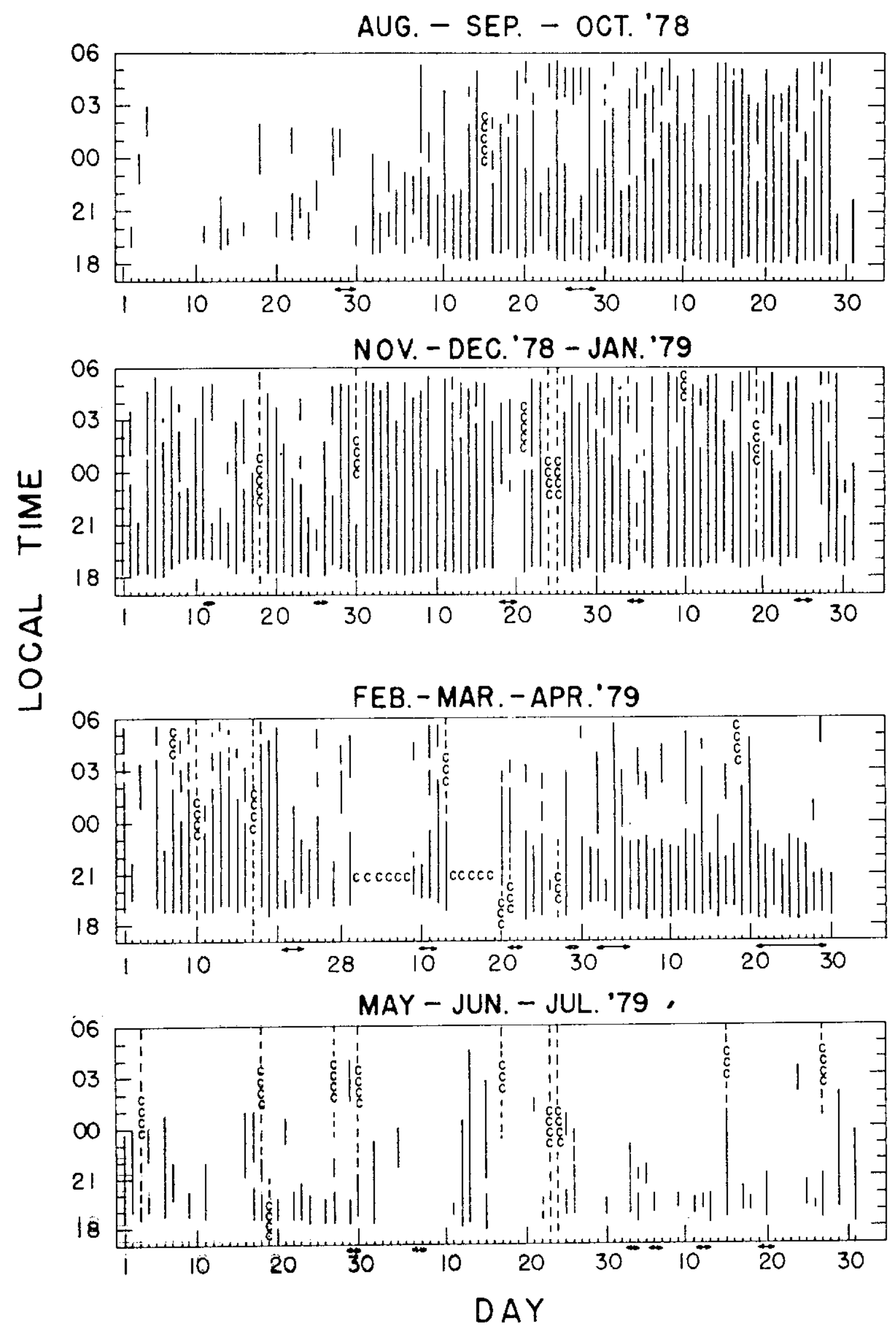

Fig. 2 


\section{FREQUENCY SPREAD}

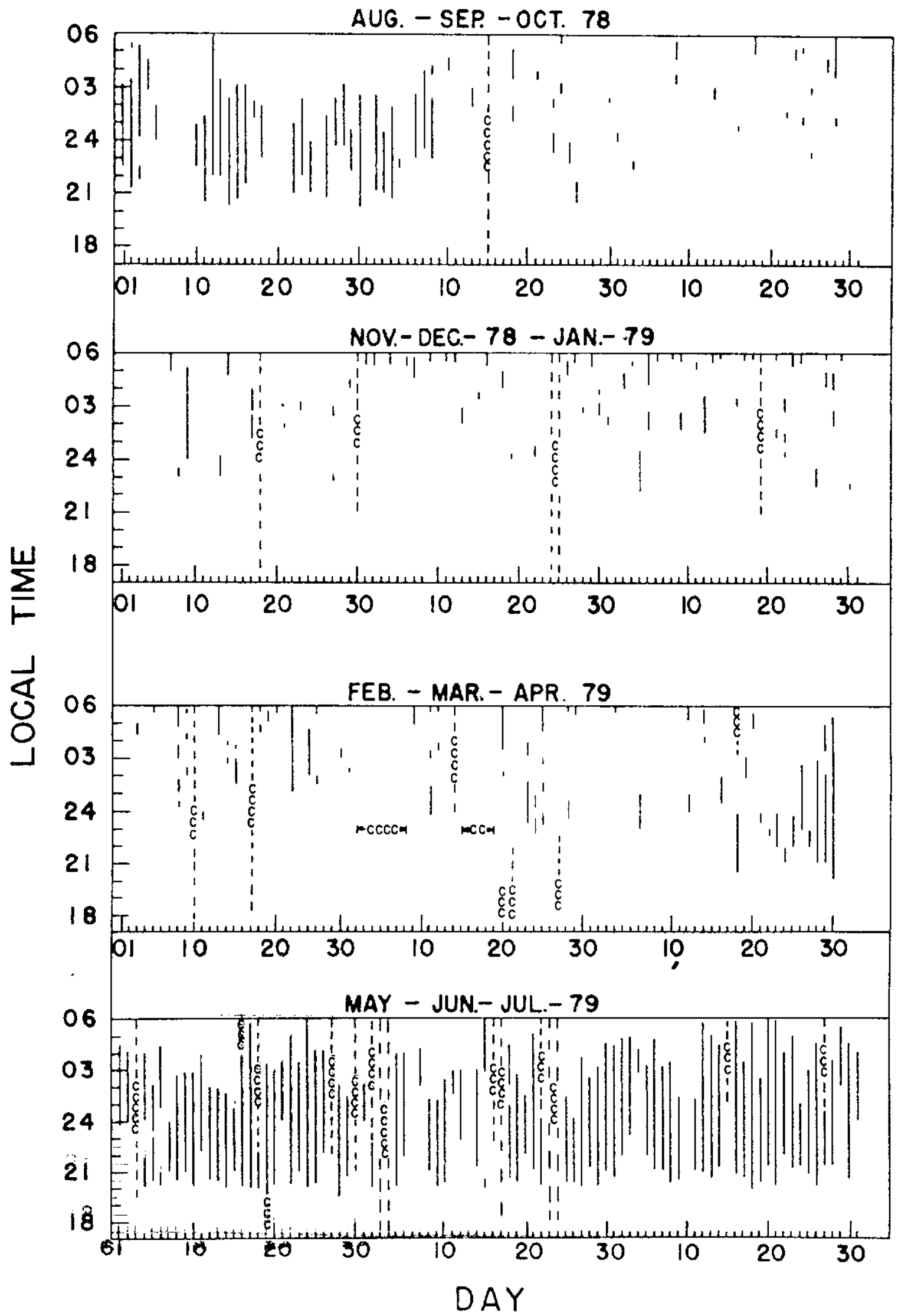

Fig. 3 


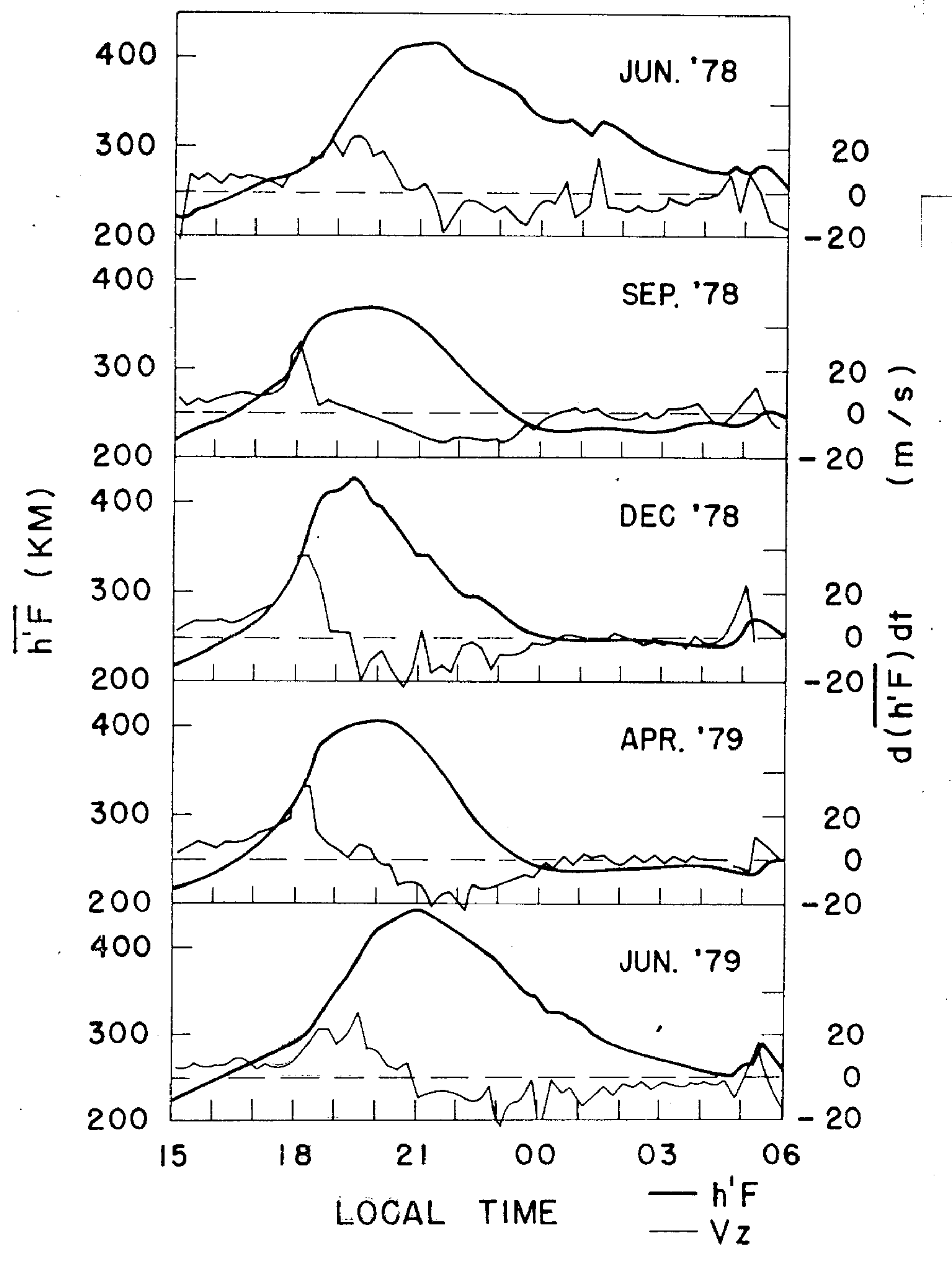

Fig. 4 